\title{
Filing for Moral Bankruptcy: An Examination of How Affect and Empathy Predict Moral Competence
}

\author{
Nicholas Surdel \\ (University of Florida, Gainesville, n.a.surdel@gmail.com) \\ Marina A. Klimenko \\ (University of Florida, Gainesville, mklimenko@ufl.edu)
}

\section{Introduction}

What is morality and what makes people act morally (or immorally)? These questions have been the focus of many debates and studies throughout psychology. One area of a continued inquiry is around the question of stability of adult morality and the possible factors that may increase or decrease it. Empathy is one of such factors that seem to explain some individual differences in moral reasoning. However, given the fact that empathy is a multi-dimensional construct, its contribution to moral reasoning is still poorly understood. Another potential variable that may lead to fluctuation in moral reasoning is the affective state (e.g., feeling positive or negative emotions). For example, studies in which participant's affective state was manipulated experimentally, (e.g., by invoking a feeling of disgust, see Wheatley \& Haidt 2005), found that moral judgment had changed as well (e.g., they made more severe moral judgments). Even more is unknown about the relative contribution of both, empathy and affective state, on the adult moral judgment. The present study was designed to address this question.

\subsection{Moral competence}

Arguably, the most influential theory of moral development has been put forth by Kohlberg who theorized that individuals go through universally the same and invariant stages of moral development. Specifically, the first pre-conventional stage is rooted in satisfying one's needs only. This stage contains two sub-stages: punishment and obedience-oriented morality and the instrumental relativist orientation, which is anecdotally referred to as the popular saying, "you scratch my back and I will scratch yours". The second stage is the conventional level of morality, in which the primary focus is to maintain the expectations and conventions of one's societal norms. The first sub- 
stage of the conventional level is the interpersonal concordance orientation, which can be described by the emergence of consideration for other's intentions. The following sub-stage is the "law and order" orientation, in which social order's maintenance is the top priority. The final stage is the post-conventional level, in which the individual's moral values and principles are oriented towards what is just and fair. The first substage under this is the social-contract legalistic orientation, which is markedly different from the previous stage because now the individual may hold that certain laws could be changed in favor of social utility. Then the final sub-stage is the universal ethical-principle orientation, which is defined by the individual possessing a universal humanitarian outlook (Kohlberg \& Kramer 1969; Kohlberg 1971). This morality stage-theory received a considerable amount of both, support and criticism. For example, despite the presence of some elements of cultural and social biases in the measures of moral reasoning, most cross-cultural studies of at least 20 different cultures and at least seven longitudinal studies found confirmation to an upward trend in moral development as outlined in the theory (see Snarey 1985). Furthermore, the presence of at least 5 stages of moral reasoning were found in almost all studied cultures when age differences were controlled (see Snarey 1985).

However, most all reported cultural studies have significant methodological issues, such as having small sample sizes or relying on cross-sectional rather than longitudinal observations, and the failure to control for various demographic characteristics (e.g., social class) (Snarey 1985). Psychologist Georg Lind has criticized it for failing to properly distinguish between the affective (moral preferences) and the cognitive (pattern of moral reasoning) dimensions of moral reasoning; only the latter can be improved with education or training, and thus, should be the target of intervention, according to Lind (2000). In his dual-aspect theory of moral behavior and development, Lind (2000) refers to the affective domain as the moral orientation and the cognitive domain as the moral competence. Lind also developed a moral competence test (MCT) that allows deriving indices of both, moral orientation and moral competence. The score on the MCT test "indicates the percentage of an individual's total response variation due to a person's concern for the moral quality of given arguments or behavior" (Lind 2000,4). In other words, it provides a measure of the consistency of an individual's application of his/her moral principles in various situations.

\subsection{The link between moral competence and empathy}

Empathy has been broadly defined as the reactions to people's behavior and emotions (e.g., Davis 1983). It can be further described as cognitive (e.g., understanding another person's perspective) and emotional (e.g., feeling emotions of another person) reactions. Empathizing with another person, by feeling another's pain or being concerned about their well-being, has been theorized to motivate to act prosocially and altruistically (Pizarro 2000). Empirical evidence also suggests that empathy serves as a motivating 
factor to help others (Eisenberg \& Miller 1987). Davis (1983), however, argues that different dimensions of empathy will have a different effect on the social behavior. For example, perspective taking, is likely to have a positive contribution due, in part, to inciting nonegocentric behaviors; whereas personal distress, characterized by anxiety from seeing another person in distress, will have an opposite effect due to preoccupation with one's own feelings (Davis 1983).

While there is a large body of literature demonstrating an existing link between empathy and prosocial behavior (e.g., Tangney 1991), surprisingly, very few studies (only three known to the authors) have examined the direct link between empathy and moral reasoning. One comes from a study of 149 Brazilian adolescents, by Eisenberg, Zhou, and Koller (2001), and that the study found that perspective taking, was positively predictive of prosocial moral reasoning. Another study was conducted by Skoe (2010) and found that individuals with higher perspective taking showed higher level of carebased moral reasoning. In the same study, personal distress was positively associated with chronic fearfulness and emotional vulnerability which, one can speculate, may cause preoccupation with one's self and feeling of shame, and lead to risky, socially undesirable behavior (e.g., Tangney, Stuewig \& Mashek 2007). Finally, Berenguer (2007; 2010) demonstrated experimentally that inducing participants to feel more empathy led to a helping behavior (i.e., money donation to an environmental program) and to more moral arguments about environmental dilemmas.

Given the theory and empirical evidence, the prediction of the present study was that moral competence would be positively correlated with perspective taking and negatively correlated with personal distress.

\subsection{The link between moral competence and affective state}

Long before psychology was a field, famed philosophers Immanuel Kant and David Hume speculated about the driving force behind morality. Kantian ideology held that dispassionate reason drove the moral decision-making process. He stood firm that a moral decision was founded solely upon the utilitarian mindset and therefore was uninfluenced by affective factors (Kant 1785). Thus, according to his view, moral competence should not be affected by the affective state of the person making a moral decision. Alternatively, Hume held that passions drove moral judgments. He argued that people are susceptible to being influenced and deceived, or "clouded", by an array of factors including one's emotions (Hume 1751). This debate is far from being resolved. Psychologist David Pizarro (2000), for example, argues that affective arousal is a necessary condition for people to recognize an act as immoral and to begin moral deliberation. Similarly, Frijda (1988) argues that emotions are "lawful phenomena"; they are aroused for things we care about and are absent when we don't care about something. Pizarro (2000) refers to emotions as an "energy source" that forces individuals to make a moral judgment; but he agrees with those who believe that affective arousal is the most effective at promoting moral 
reasoning if it is regulated (e.g., Gross 1999). Inspired by Hume's philosophy, Jonathan Haidt's social intuitionist model necessitates moral emotions (Haidt 2001). Haidt draws from cultural, evolutionary, social, and biological psychology to demonstrate that the first step in any moral decision making is an emotional intuition, followed by logical reasoning (See Schweder, Much, Mahapatra, \& Park 1998; Menon \& Schweder 1998; Bechara, Damasio, \& Damasio 2000).

Experimental studies have demonstrated that affect can influence people's moral judgments. For example, disgust-induced participants found moral transgressions to be significantly more off-putting, resulting in the transgressions being judged more harshly (Wheatley \& Haidt 2005). Positive feelings, on the other hand, have been shown to promote more prosocially-oriented behavior and decisions (e.g., Dovidio, Gaertner, Isen, \& Lowrance 1995). One possible explanation is from the mood-management perspective, that suggests that people are motivated to act on something in order to maintain or to repair their negative mood (e.g., being personally distressed by another person's misfortune) (Batson \& Powell 2003). On the other hand, there is evidence suggesting that when feeling happy, people tend to rely on heuristics, so called mental short cuts, when they make decisions, which may result in less accurate judgments or biases (e.g. Bodenhausen, Mussweiler, Gabriel, \& Moreno, in press; Dovidio, Gaertner, Isen, \& Lowrance 1995). Negative mood has shown to have an inversive effect. For example, according to Schwarz and Bless (1991), negative affect induces an analytical mindset with enhanced detail acuity. Ramifications of this mindset include a heightened degree of logical consistency, which may result in elevation of moral reasoning. However, there is also research showing that negative states like anger is predictive of aggressive behavior, punitive judgments, and blaming of others (see Eisenberg 2000).

Thus, the literature is still inadequate in terms of explaining the link between various positive and negative affective states and moral reasoning. Thus, the present study hypothesized that the negative and positive affective states would be related to moral competence, however no hypotheses were made as to the nature of these associations.

\section{Methods}

\subsection{Sample}

Students who were enrolled in an online University of Florida undergraduate online course were recruited to participate. The sample size was selected based on the feasibility of collecting the data within one academic summer semester. Out of 68 enrolled in the class students, 51 agreed to participate, which represents $75 \%$ of the class population. A power calculation demonstrated that the current sample size produced a statistical power of 90\%. In the sample, there were 41 females and 10 males. The participants were between age 18 and 40, with an average age of 23. The sample was 58\% Caucasian, 22\% Latin- 
American, and $20 \%$ other ethnicities. To avoid any perception of coercion, the primary investigator did not partake in collecting data from individuals who chose to participate. Those who did not wish to participate were offered an alternative opportunity to earn the extra credit point. All of the surveys were anonymous and administered by Qualtrics.

\subsection{Instruments}

The study consisted of two waves of surveys. The first wave, containing the Interpersonal Reactivity Index (IRI; Davis 1980) and Positive and Negative Affective State Scale (PANAS; Watson, Clark \& Tellegen 1988), was distributed at the beginning of the Summer-A 2017 semester. The IRI asked participants their preferences and attitudes on several scenarios to measure their emotional and cognitive empathy. The PANAS typically consists of 10 positive and 10 negative adjectives, however, due to err we excluded "Proud" - a positive affective adjective. Participants were instructed to rate their feelings during the past few days by rating the adjectives on 5-point Likert scales.

The second wave, containing the IRI (Davis 1980), PANAS Scale (Watson et al. 1988), and Moral Competence Test instrument (MCT; Lind 2014) (This instrument measures moral competence and moral orientation by presenting moral dilemmas and asking participants to rate their level of being in agreement with several arguments for and against certain decisions), was sent out at the end of the semester. The demographic data collected includes the participants' sex, ethnicity, and age.

\section{Results}

Means for the major variables are presented in Table 1. In these analyses, all significant tests are two-tailed unless otherwise stated.

\subsection{Descriptive statistics and preliminary analyses}

Paired samples T-tests were computed to examine if empathy and affective states changed over time (see Table 1). The test revealed that only personal distress was significantly different between the two assessments. Descriptive statistics show that moral competence scores ranged between .33 to 43.49 , with a mean of 11.3 and standard deviation of 10.1. When interpreting these numbers, the higher the score is, the higher the moral competence exhibited is. These results are comparable to other contemporary studies (see Liaquat 2013; Lee 2010). 


\begin{tabular}{|c|c|c|c|c|c|c|c|c|}
\hline \multirow[b]{2}{*}{ Outcome } & \multicolumn{2}{|c|}{ Time 1} & \multicolumn{2}{|c|}{ Time 2} & \multirow[b]{2}{*}{$\mathrm{n}$} & \multirow{2}{*}{$\begin{array}{l}95 \% \text { CI } \\
\text { for Mean } \\
\text { Difference }\end{array}$} & \multirow[b]{2}{*}{$\mathrm{t}$} & \multirow[b]{2}{*}{$\mathrm{df}$} \\
\hline & M & SD & M & SD & & & & \\
\hline Fantasy & 2.72 & .88 & 2.67 & .86 & 50 & $-0.00, .22$ & 1.927 & 49 \\
\hline $\begin{array}{l}\text { Perspective } \\
\text { taking }\end{array}$ & 2.78 & .62 & 2.78 & .59 & 51 & $-0.11,0.09$ & -.120 & 50 \\
\hline $\begin{array}{l}\text { Empathic } \\
\text { concern }\end{array}$ & 3.01 & .62 & 2.99 & .66 & 48 & $-0.06,0.11$ & .547 & 47 \\
\hline $\begin{array}{l}\text { Personal } \\
\text { distress }\end{array}$ & 1.42 & .63 & 1.27 & .55 & 48 & $.06,0.31$ & $2.919 *$ & 47 \\
\hline Positive affect & 28.14 & 7.63 & 27.88 & 8.33 & 51 & $-1.45,1.96$ & .300 & 50 \\
\hline Negative affect & 20.57 & 7.78 & 21.06 & 7.80 & 51 & $-2.34,1.36$ & -.533 & 50 \\
\hline
\end{tabular}

Table 1: Descriptive Statistics and t-test Results for Fantasy, Perspective taking, Empathic concern, Personal distress, Positive affect, and Negative affect

Thus, all empathy scores, except for personal distress, and both affective states were averaged to be used in subsequent analyses. Next, bivariate correlations were computed to examine the associations between empathy, affective states, age, sex and moral competence. The results revealed that only fantasy, perspective taking, and negative affective state were significantly (positively) correlated with moral competence (see Table 2). In addition, bivariate correlations revealed a significant positive association between perspective taking and positive affect; while positive affect negatively associated with personal distress (at both time 1 and time 2); and negative affect was positively correlated with empathic concern and with personal distress (at time 1).

\begin{tabular}{rlllllllll}
\hline & Fant & PT & EC & PD T1 & PD T2 & PAS & NAS & Sex & Age \\
\hline Moral Competence & $.357^{*}$ & $.499^{* *}$ & .244 & .099 & -.129 & -.041 & $.278^{*}$ & .142 & .029 \\
\hline${ }^{*} p<.10 .{ }^{* * p}<.05 .{ }^{* * *} p<.01$. & & & & & & & &
\end{tabular}

Table 2: Bivariate Correlations Between the Variables

\subsection{Multiple regression analyses}

A stepwise multiple regression was conducted to find the best combination of predictors of moral competence among the two affective states and four empathy dimensions. At step 1 of the analysis, perspective taking empathy entered the regression equation first as the strongest predictor of moral competence; explaining $24.9 \%$ of the variance in the moral competence, $\mathrm{R} 2=.25, \mathrm{~F}(1,44)=14.60, \mathrm{p}=.000$. At step 2 of the analysis, negative affective state entered the regression equation as the second and the final predictor of moral competence, $\mathrm{R} 2=.32, \mathrm{~F}(2,43)=10.07, \mathrm{p}=.000$. Thus, together, perspective taking and negative affect explained approximately $32 \%$ of the variance in the moral competence. No other predictors entered the model. 


\subsection{Discussion}

The present study was set to examine the relative contributions of affective states and empathy to moral competence.

As predicted, perspective taking was positively correlated with moral competence. Furthermore, it was the strongest and the only significant empathy-related predictor. Negative affect was the second and also a positive predictor of moral competence, thus, supporting the mood and cognition theory by Schwartz and Bless (2001) which asserts that people in a negative mood are more attentive to details; since staying consistent in one's moral judgment requires focused attention, feeling more negative can help to stay focused and avoid heuristics.

Unlike predicted, personal distress was not associated with moral competence, however, there are several possible explanations for that. First, self-reports may not always be reliable as they may be confounded with the desire to appear in more socially desirable ways (e.g., Archer, Diaz-Loving, Gollwitzer, Davis, \& Foushee 1981). Second, all past known studies have studied the link between personal distress and prosocial behavior (e.g., motivation to help); while moral competence should be related to prosocial behavior, it is a different act all together. It is possible that while personal distress may reduce the likelihood of acting prosocially, its effect on moral reasoning may be quite different. Finally, the reason why individuals who become more personally distressed over a misfortune of a victim are less likely to act prosocially is to escape the unpleasantness of being in distress; thus, one can assume that the cause of the distress must be related to the motivation (or lack thereof) to act prosocially, including judging on a moral dilemma. In the present study, personal distress was potentially unrelated to the moral dilemmas given to the participants; the timing when the subjects took the survey the second time coincided with their final exams, thus, potentially explaining the inconsistency in personal distress scores.

Overall, the findings of this study suggest that morally competent individuals are those who can better understand other's mental states rather than those who can emotionally empathize. Furthermore, the findings of this study suggest that emotions do not always impede moral judgment; at least in the case of negative affect, they can help direct people to the details of the situation at hand which can in turn improve their moral reasoning. Future studies will have to further differentiate between different types of negative emotions and their relationship with moral competence and reasoning. For example, it is not clear whether sadness behaves consistently with disgust. Finally, given prior literature and the findings of the present study, perspective taking emerges as an important element in both, moral reasoning and prosocial behavior; and as such should be examined more in depth in developmental research. This is especially true when seeking to explain individual differences in moral behavior (e.g., bullying, moral disengagement, etc.). 


\section{References}

Batson C. D. \& Powell A. A. 2003. "Altruism and Prosocial Behavior”, in T. Millon \& M. J. Lerner (Eds.), Handbook of Psychology: Personality and Social Psychology, Vol. V. Hoboken, NJ: Wiley \& Sons (463-84).

Bechara A., Damasio H., \& Damasio A. 2000. "Emotion, Decision Making, and the Orbitofrontal Cortex." Cerebral Cortex 10(3):295-307.

Berenguer J. 2010. "The Effect of Empathy in Environmental Moral Reasoning." Environment and Behavior 42(1):110-34.

Bodenhausen G. V., Mussweiler T., Gabriel S., \& Moreno K. N. (in press). "Affective Influences on Stereotyping and Intergroup Relations," in J. P. Forgas (Ed.), Handbook of Affect and Social Cognition.

Davis M. H. 1980. "A Multidimensional Approach to Individual Differences in Empathy." JSAS Catalog of Selected Documents in Psychology 10:85.

Davis M. H. 1983. "Measuring Individual Differences in Empathy: Evidence for a Multidimensional Approach." Journal of Personality and Social Psychology 44(1):113-26. doi:10.1037/0022-3514.44.1.113.

Dovidio J. F., Gaertner S. L., Isen A. M., \& Lowrance R. 1995. “Group Representations and Intergroup Bias: Positive Affect, Similarity, and Group Size.” Personality and Social Psychology Bulletin 21(8):856-65. doi:10.1177/014616729521009.

Eisenberg N. 2000. "Emotion, Regulation, and Moral Development." Annual Review of Psychology 51:665-97.

Eisenberg N. \& Miller P. A. 1987. "The Relation of Empathy to Prosocial and Related Behaviors." Psychological Bulletin 101(1):91-119.

Eisenberg N., Zhou Q., \& Koller S. 2001. “Brazilian Adolescents' Prosocial Moral Judgment and Behavior: Relations to Sympathy, Perspective Taking, GenderRole Orientation, and Demographic Characteristics." Child Dev. 2001 Mar-Apr; 72(2):518-34.

Frijda N. H. 1988. "The Laws of Emotion." American Psychologist 43(5):349-58. doi:10.1037/0003-066X.43.5.349.

Gross J. J. 1999. “Emotion and Emotion Regulation,” in L. A. Pervin \& O. P. John (Eds.), Handbook of Personality: Theory and Research. New York: Guilford Press (525-52).

Haidt J. 2001. "The Emotional Dog and Its Rational Tail: A Social Intuitionist Approach to Moral Judgment." Psychological Review 108(4):814.

Hume D. $1751^{1}$. Enquiry Concerning the Principles of Morals; selections in Raphael, Vol. II (1991).

Kant I. 1785¹/1998. Groundwork for the Metaphysics of Morals. New York: Cambridge University Press.

Kohlberg L. \& Kramer R. 1969. "Continuities and Discontinuities in Childhood and Adult Moral Development." Human Development 12(2):93-120. 
Kohlberg L. 1971. “Stages of Moral Development.” In C. M. Beck, B. S. Crittenden, \& E. V. Sullivan (Eds.), Moral Education. Toronto: University of Toronto Press.

Lee Won Dong. 2010. "An Empirical Research on the Moral Judgment Competence of Korean Young Students: Focused on Comparing P-index of KDIT and C-index of MJT." Doctoral dissertation, Department of Ethics Education, Teachers College, Gyeongsang National University, South Korea.

Liaquat A. W. 2013. "Effect of Dogmatic Religiosity and Educational Environment on Moral Judgment Competence." Unpublished dissertation, Dept. of Psychology, International Islamic University Islamabad.

Lind G. 2008. "The Meaning and Measurement of Moral Judgment Competence. A DualAspect Model," in D. Fasko, Jr. \& W. Willis (Eds.), Contemporary Philosophical and Psychological Perspectives on Moral Development and Education. Cresskill: Hampton Press (185-220).

Lind G. 2014, March 24. “Moral Competence Test (MCT)," from http://www.unikonstanz.de/ag-moral/mut/mjt-engl.htm.

Menon U. \& Schweder R. A. 1998. “The Return of the »White Man's Burden«: The Moral Discourse of Anthropology and the Domestic Life of Hindu Women," in R. A. Schweder (Ed.), Welcome to Middle Age! (and Other Cultural Fictions). Chicago: University of Chicago Press (139-88).

Pizarro D. 2000. "Nothing More Than Feelings? The Role of Emotions in Moral Judgment." Journal for the Theory of Social Behaviour 30(4):355-75. doi:10.1111/1468-5914.00135.

Schwarz N. \& Bless H. 1991. "Happy and Mindless, But Sad and Smart? The Impact of Affective States on Analytic Reasoning," in J. P. Forgas (Ed.), Emotion and Social Judgment. Oxford: Pergamon (55-71).

Schweder R., Much N., Mahapatra M., \& Park L. 1998. “The »Big Three« of Morality (Autonomy, Community, and Divinity), and the »Big Three« Explanations of Suffering, As Well," in A. Brandt \& P. Rozin (Eds.), Morality and Health. Stanford, CA: Stanford University Press (119-69).

Skoe E. A. 2010. "The Relationship between Empathy-Related Constructs and Care-based Moral Development in Young Adulthood." Journal of Moral Education 39(2):191211. doi: $10.1080 / 03057241003754930$.

Tangney J. P. 1991. "Moral Affect: The Good, the Bad, and the Ugly." Journal of Personality and Social Psychology 61(4):598-607. doi:10.1037/0022-3514.61.4.598.

Tangney J. P., Stuewig J., \& Mashek D. J. 2007. “Moral Emotions and Moral Behavior." Annual Review of Psychology 58:345-72.

Watson D., Clark L. A., \& Tellegen A. 1988. "Development and Validation of Brief Measures of Positive and Negative Affect: The PANAS Scales." Journal of Personality and Social Psychology 54(6):1063-70. doi:10.1037/0022-3514.54.6.1063. 
Wheatley T. \& Haidt J. 2005. "Hypnotic Disgust Makes Moral Judgments More Severe." Psychological Science 16(10):780-4. 


\author{
Nicholas Surdel (Gainesville) \\ Marina A. Klimenko (Gainesville)
}

\title{
Filing for Moral Bankruptcy: An Examination of How Affect and Empathy Predict Moral Competence
}

\begin{abstract}
What does being moral mean? On one hand people may justify mercy killing as sparing someone's suffering, but on the other hand they are still, in-fact, taking another's life. According to Lind's theory of moral competence (2008), it is based on consistent utilization of moral principles. Although common sense tells us that people's affective states and levels of empathy may explain the differences, there is little direct evidence. The purpose of this study was to fill this gap by examining the relative contribution of empathy and affective state to moral competence. Results of the study revealed that although perspective taking and negative affective state were both significant predictors of moral competence, perspective taking was a stronger contributor. This suggests that the next time you deliberate over a moral dilemma (e.g., euthanasia), you should try understanding another person's perspective rather than feeling empathy to make the best moral judgment.
\end{abstract}

Keywords: moral competence; empathy; affect; emotions

Ethics in Progress (ISSN 2084-9257). Vol. 9 (2018). No. 2, Art. \#2, pp. 16-26.

Creative Commons BY-SA 3.0

Doi:10.14746/eip.2018.2.2 